\title{
Targeting of epigenetic regulators in neuroblastoma
}

\author{
Luz Jubierre', Carlos Jiménez ${ }^{1}$ Eric Rovira', Aroa Soriano ${ }^{1}$, Constantino Sábado², Luis Gros², Anna Llort², \\ Raquel Hladun ${ }^{1,2}$, Josep Roma', Josep Sánchez de Toledo ${ }^{1,2}$, Soledad Gallego ${ }^{1,2}$ and Miguel F. Segura (i)
}

\begin{abstract}
Approximately 15,000 new cases of pediatric cancer are diagnosed yearly in Europe, with 8-10\% corresponding to neuroblastoma, a rare disease with an incidence of 8-9 cases per million children $<15$ years of age. Although the survival rate for low-risk and intermediate-risk patients is excellent, half of children with high-risk, refractory, or relapsed tumors will be cured, and two-thirds of the other half will suffer major side effects and life-long disabilities. Epigenetic therapies aimed at reversing the oncogenic alterations in chromatin structure and function are an emerging alternative against aggressive tumors that are or will become resistant to conventional treatments. This approach proposes targeting epigenetic regulators, which are proteins that are involved in the creation, detection, and interpretation of epigenetic signals, such as methylation or histone post-translational modifications. In this review, we focused on the most promising epigenetic regulators for targeting and current drugs that have already reached clinical trials.
\end{abstract}

\section{Introduction}

Cancer therapy underwent a drastic change in the 20th century. The spread of anesthesia in the 1840s eased surgical procedures and added to the introduction of radiotherapy in the early 1900's, and the discovery of chemotherapeutics during World War II caused this field to grow exponentially ${ }^{1}$. Most of these approaches act by targeting DNA or DNA-related proteins, which produce alterations that become lethal, particularly in dividing cells. However, the efficacy of these strategies is not optimal because cancer remains one of the main causes of death in developed countries, and the toxicity and high mutagenic potential of many of these therapeutic agents render them highly uncomfortable with many undesired side effects $^{2-4}$. These deficiencies have prompted the search for targeted therapies that aim to inhibit elements that are involved in signaling pathways or mechanisms

\footnotetext{
Correspondence: Miguel F. Segura (miguel.segura@vhir.org) ${ }^{1}$ Group of Translational Research in Child and Adolescent Cancer, Vall d'Hebron Research Institute, Passeig Vall d'Hebron 119, 08035 Barcelona, Spain

${ }^{2}$ Vall d'Hebron Hospital, Passeig Vall d'Hebron 119, 08035 Barcelona, Spain
}

that are specific to the tumor and responsible for its tumorigenic features. However, in many cases, cancer cells are able to evade the effect of a specific targeted therapy using independent mechanisms, eventually resulting in drug resistance ${ }^{5}$. To overcome this challenge, cancer research also focuses on multi-target therapies aimed at disrupting multiple cancer pathways with combinations of specific drugs ${ }^{6-8}$.

Epigenetic therapies are an emerging option for overcoming drug resistance. This approach proposes targeting of epigenetic regulators, which are proteins involved in the creation, detection and interpretation of epigenetic signals. The term epigenetics refers to all of the chemical changes that can modulate gene expression and can be transmitted through mitosis and meiosis without altering the nucleotide sequence ${ }^{9}$. The main epigenetic signals are DNA methylation, histone modifications and RNAassociated silencing. These processes are responsible for the specific expression of certain sets of genes that must be transcribed at a certain dose and at a particular time. The inhibition of one epigenetic regulator could have the same effect on several cell processes as if all of these 
pathways were individually targeted with a specific drug. A further advantage of epigenetic therapies is that they act at the transcriptional level, which enables the repression of certain genes or the transcriptional reactivation of genes epigenetically silenced in cancer ${ }^{10,11}$. In the recent two decades, interest in development and validation of drugs that target epigenetic regulators has continued to increase. Selected compounds have already been approved for treatment of certain tumors, and many other compounds are currently at a pre-clinical stage or already under clinical trials ${ }^{12-17}$. All of these advances render epigenetic therapies a promising alternative for cancers in which survival rates are still poor due to resistance to current treatments.

High-risk neuroblastoma is one of the malignancies that often become refractory to current therapies and for which epigenetic therapies could be useful. Neuroblastoma (NB) is an embryonal tumor of the sympathetic nervous system and is the most common extracranial solid tumor of childhood, causing $12-15 \%$ of pediatric cancer deaths in European populations. This disease appears mainly in the adrenal glands, and in advanced stages, it can disseminate to distant lymph nodes, bone, bone marrow, liver, and skin. Neuroblastoma patients are classified according to disease stage and molecular alterations into three groups: low, intermediate, and high risk. Although the first two groups show five-year survival rates greater than $90 \%$, the survival of high-risk patients remains poor at approximately $40 \%$. Despite aggressive treatment consisting of surgery and a combination of high-dose chemotherapy, radiotherapy and immunotherapy, the survival rate of high-risk neuroblastoma remains notably low ${ }^{18,19}$. Therefore, high-risk NB is a good candidate for epigenetic therapies to overcome drug resistance.

Currently, most epigenetic drugs act at three main levels (Fig. 1): (i) DNA methylation, which can be modulated by targeting of DNA methyltransferases (DNMT); (ii) histone modifications, such as acetylation and methylation, which can be targeted by inhibiting the enzymes responsible for these chemical changes; and (iii) blockage of the interpretation of these modifications by targeting epigenetic readers, among which proteins containing bromodomains are the most thoroughly characterized. In this review, we offer an accurate compilation of the current status of epigenetic therapy research for neuroblastoma treatment and highlight the most promising therapeutic targets and potential drugs involved in these three epigenetic levels.

\section{DNA methylation}

The bases of the epigenetic field were founded on the study of DNA methylation in the 1960s. DNA methylation leads to stable long-term transcription repression, whereas unmethylated DNA tends to remain in a more relaxed structure, thereby facilitating entry of the replicative and transcription machinery ${ }^{20}$. For methylation to occur, four DNA methyltransferases (DNMT1, DNMT3a, DNMT3b, and DNMT3L) exist in mammals, and the activity of these methyltransferases consists of transfer of a methyl group from S-adenosyl-L-methionine to the C5 position of cytosine residues (Fig. 2a). DNMT are capable of performing de novo methylation when the initial pattern is set during embryogenesis and perpetuating this methylation throughout the individual's life. DNMT3A and $\mathrm{B}$ are considered the de novo DNMT. However, DNMT1 is responsible for maintaining methylation in the daughter DNA strand during replication. Finally, DNMT3L is a related protein lacking catalytic activity that stimulates de novo methylation by DNMT3A and is required for the establishment of maternal genomic imprints (previously reviewed ${ }^{21}$ ).

The association between DNA methylation and cancer was established soon after discovery. In 1965, Craddock and Magee analyzed DNA methylation in the liver during carcinogenesis $^{22}$, and one year later, Silber et al. described methylation in normal and leukemic leukocytes ${ }^{23}$. Currently, aberrant DNA methylation patterns have been observed in many different cancers.

The expression of DNMTs have been shown to be altered in neuroblastoma. Particularly, DNMT3A/B expression was observed to be higher in high-risk $\mathrm{NB}$ tumors and overexpressed in cisplatin-resistant NB cells $^{24}$. Recently, a truncated form of DNMT3B, i.e., DNMT3B7, was identified in primary NB tumors. Interestingly, although DNMT3B expression correlates with NB with poor outcome, DNMT3B7 expression was associated with better clinical behavior. In fact, ectopic expression of DNMT3B7 in NB cells inhibited tumor growth in vivo by reducing cell proliferation and increasing apoptosis. Furthermore, reduced tumor vascularity was also observed. Genomic and transcriptomic analyses revealed that DNMT3B7-overexpressing cells had higher levels of genomic methylation and increased expression of genes related to the retinoic acid pathway. Consistent with these findings, treatment of DNMT3B7overexpressing cells with all-trans retinoic acid enhanced NB differentiation ${ }^{25}$. Why DNMT3A/B and DNMT3B7 have opposite roles and whether these DNMT target different genomic regions remain to be elucidated.

Nevertheless, general increased genomic methylation is associated with poor outcome in $\mathrm{NB}^{26}$. Therefore, the use of DNMT inhibitors (DNMTi) might offer new alternatives for patients who do not respond to current therapies. One of the first DNMTi tested in NB cells was 5-aza-deoxycytidine (5-aza or decitabine), a chemical analog of the nucleoside cytidine. Treatment of NB cells with 5 -aza showed induced cell differentiation ${ }^{27}$ and 
$=$ Methyl group

$=$ Acetyl group

2. Histone modifications

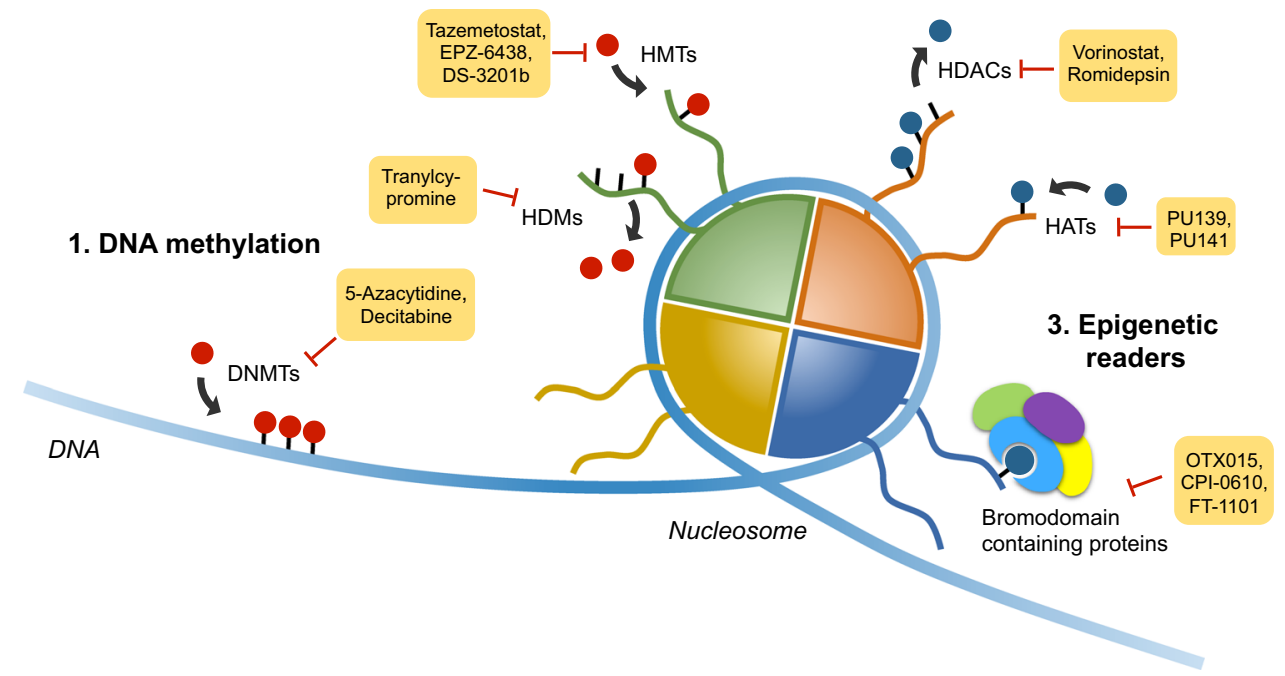

Fig. 1 Main epigenetic targets. Current inhibitors act on three different epigenetic levels: DNA methylation, histone methylation or acetylation, and chromatin reading. This scheme highlights the most promising drugs that target proteins involved in these processes with a subset already under clinical trials or even approved for treatment of certain malignancies

reduced proliferation and colony formation ${ }^{27,28}$. Further studies demonstrated that 5 -aza can potentiate the cytotoxic effects of current chemotherapies, such as doxorubicin, cisplatin and etoposide ${ }^{29}$, thereby suggesting that a combination of 5-aza with standard therapies could lead to more effective and safer treatments. However, a phase I clinical study of decitabine with doxorubicin showed that only low-doses of decitabine with this combination were tolerable and that those capable of producing clinically significant biologic effects were not well tolerated ${ }^{30}$.

These results suggest that more specific DNMTinhibitors might offer better safety profiles. Recently, two new DNMT inhibitors, i.e., SGI-1027 (selective for DNMT1, DNMT3A/B) and nanaomycin A (DNMT3Bspecific), displayed higher cytotoxic effects alone or in combination with doxorubicin but without alteration of general genome methylation ${ }^{31}$. The use of these new inhibitors is expected to result in fewer side effects.

\section{Histone modifications}

Histones are the evolutionary solution to compaction of large amounts of DNA in the nucleus of eukaryotic cells. Approximately $147 \mathrm{bp}$ of DNA are wrapped in histone octamers (formed by H2A, H2B, H3, and H4) to form a nucleosome. Nucleosomes are assembled in successively higher-order structures to eventually form a chromosome. Nucleosomes build chromatin, which can exist as euchromatin (decondensed and transcriptionally active) or heterochromatin (condensed and transcriptionally inactive). The compaction of chromatin is regulated by modifications on the histone tails. The N-terminal and Cterminal domains protrude from the nucleosome and are subjected to different covalent post-transcriptional modifications, such as methylation, acetylation, phosphorylation, and sumoylation. The enzymes responsible for these covalent modifications are known as "writers", whereas the enzymes that remove these marks are referred to as "erasers". Finally, enzymes capable of recognizing histone marks are denoted as "readers" (reviewed in ref. ${ }^{32-34}$ ) (Fig. 1).

\section{Histone methyltransferases}

Histone methyltransferases (HMT) are a class of histone writers that transfer methyl groups from S-adenosyl methionine to histone-specific lysine or arginine residues on the histones ${ }^{35,36}$. Histone methylation is involved in different processes, such as chromatin compaction, $\mathrm{X}$ chromosome inactivation, genomic imprinting and repression, or activation of transcription, among other tasks. These functions are influenced by the site and degree of methylation on specific residues (reviewed in previous work ${ }^{36,37}$ ). Histone methylation usually occurs on the $\mathrm{H} 3$ and $\mathrm{H} 4$ tails.

To date, approximately 60 HMTs have been identified. HMT are classified depending on the histone amino acid that is methylated, and lysine methyltransferases (PKMT) modify lysine residues by mono-methylation, di-methylation, or tri-methylation and are classified in a SET 

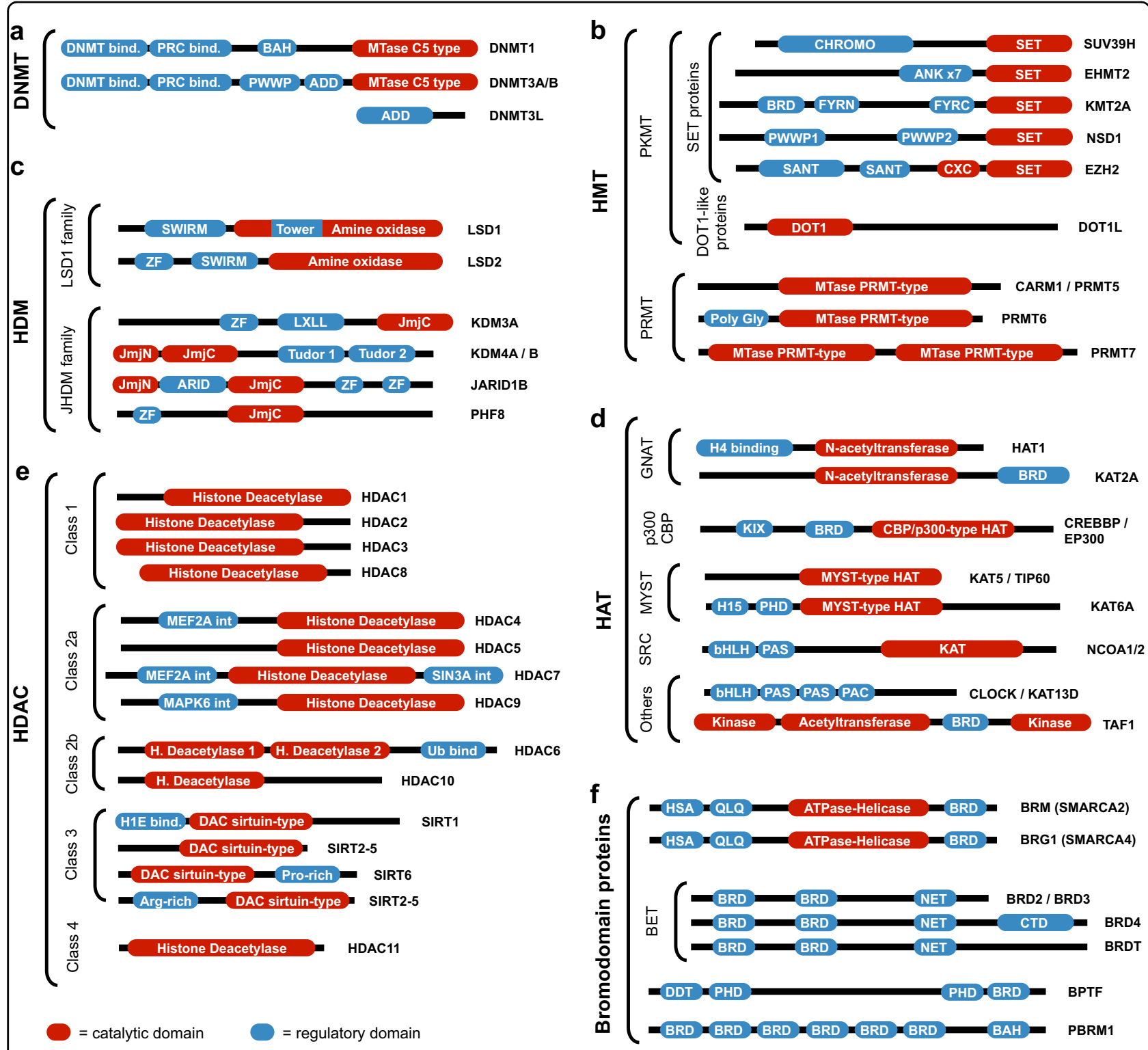

Fig. 2 Schematic representation of members of the main epigenetic regulator families and subfamilies. Representative members of a DNMT, b HMT, $\mathbf{c} H D M, \mathbf{d} H A T$, e HDAC, and $\mathbf{f}$ BRD-containing proteins are included, showing their domain configurations and indicating the catalytic region, which is the main target of epigenetic drugs. Sources: UniProt ${ }^{104}$, InterPro $^{105}$

domain-containing or a non-SET domain-containing PKMT $^{35,36}$. Arginine residues are mono-methylated and symmetrically or asymmetrically di-methylated by arginine methyltransferases (PRMT) ${ }^{38}$ (Fig. 2b).

In the last decade, certain SET-PKMS have been associated with prognostic factors, although the functional significance of these alterations remain to be determined.

Nonetheless, PKMT inhibitors show therapeutic potential in NB. This is the case of BIX-01294, a specific inhibitor of EHMT2 and a protein frequently overexpressed in several tumor types. Treatment of NB cells with BIX-01294 showed decreased cell proliferation, inhibition of cell mobility and invasion ${ }^{39}$, induction of apoptosis in vitro and reduced tumor growth in preclinical mouse models ${ }^{40}$.

\section{Histone demethylases}

Histone methylation represents a balance resulting from the opposing activity of HMT and histone demethylases (HDM). KDM1 (also known as LSD1) was the first enzyme found to be capable of removing the methyl group from mono-methylated and di-methylated Lys 4 in histone $3(\mathrm{H} 3 \mathrm{~K} 4 \mathrm{me} 1 / 2)^{41}$. HDM can be divided into two lysine HDM families: (i) the KDM1 family and (ii) the 


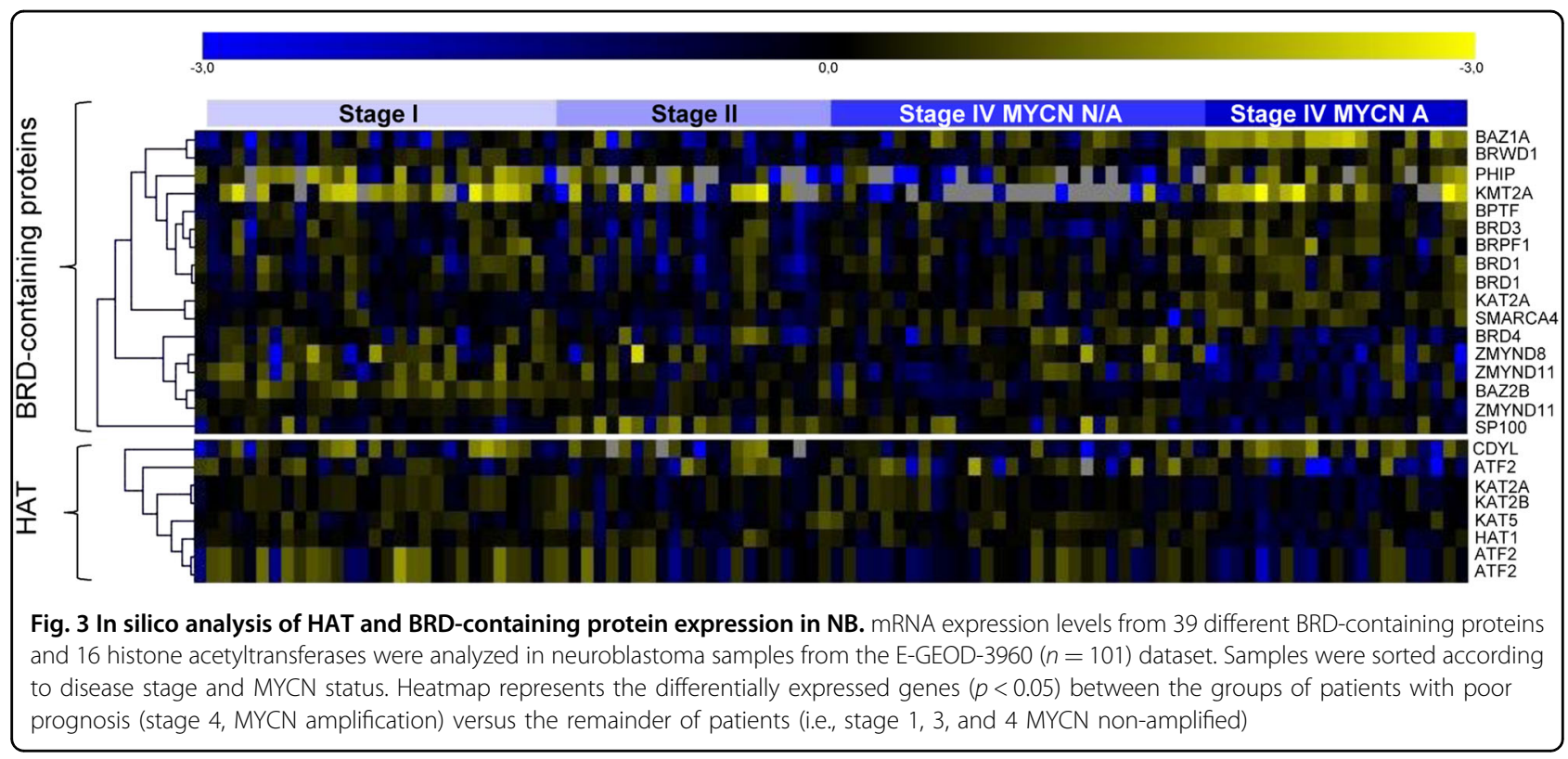

JHDM family. Although proteins from the KDM1 family demethylate mono-methylated or di-methylated lysines, those of the JHDM family demethylate tri-methylated lysines. Of note, JMJD6 (a member of the JHDM family) is also an arginine-specific HDM that demethylates H3R2me1/2 and H4R3me1/2 ${ }^{42}$ (Fig. 2c).

KDM1A was the first HDM, the expression of which was found to correlate with adverse outcome and undifferentiated tumors. Loss-of-function experiments showed that KDM1A silencing resulted in a reduction in cell proliferation, colony formation, migration and invasion of NB cell lines ${ }^{43,} 44$.

Several KDM1A inhibitors have been designed, but only trans-2-phenylcyclopropylamine (TCP) derivatives have advanced into early phase clinical trials. However, the therapeutic potential of these compounds in neuroblastoma animal models or in clinical trials remains to be addressed.

The JHMD family is larger than the KDM1A family, and therefore, more members of the family are associated with $\mathrm{NB}$. One of such examples is the KDM4B found in a search for mediators of oncogenic functions of MYCN. KDM4B knockdown reduced NB cell proliferation and induced differentiation in vitro and in vivo ${ }^{45}$. Mechanistically, KDM4B physically interacts with MYCN, removes histone methylation marks at MYCN binding sites, and blocks the transcription of MYCN direct targets, such as the miR-17-92 cluster, CDC25A, TRIP13, and VCAN $^{45}$.

\section{Histone acetyltransferases}

A further histone modification is the addition of acetyl groups from acetyl-CoA to specific histone lysine residues. This process can be performed by histone acetyltransferases $(\mathrm{HAT})^{46}$. HAT are capable of modulating gene transcription by altering histone acetylation patterns ${ }^{47,48}$ or by acetylating non-histone substrates, such as transcription factors (reviewed in ref. ${ }^{49}$ ). HAT are usually classified based on sequence similarity and structure to define five families: GNAT, p300/CBP, MYST, SRC (nuclear receptors coactivators) and others (reviewed in ref. ${ }^{50}$ ) (Fig. 2d).

To date, no HAT expression or functional studies have been conducted either in clinical or preclinical NB models. Nevertheless, in silico analyses did show that several HAT are differentially expressed in advanced stages of NB. In most cases, HAT levels are expressed at lower levels in patients with poor prognosis (i.e., stage 4 with MYCN amplified), thereby indicating that strong criteria for selection of patients who could benefit from these therapies must be considered (Fig. 3).

Nevertheless, three HAT inhibitors have been tested in NB models: PU139 (a HAT pan-inhibitor ${ }^{51}$ ), PU141 (a CBP and p300 selective inhibitor ${ }^{51}$ ), and BF1 (an H3acetylation protein inhibitor ${ }^{52}$ ). All of these inhibitors reduced NB cell growth in vitro ${ }^{51,52}$, but only PU139 and PU140 were demonstrated to reduce tumor growth in vivo ${ }^{51}$. Furthermore, PU139 showed synergism with doxorubicin in vivo, thereby blocking tumor growth ${ }^{51}$.

\section{Histone deacetylases}

Histone acetylation and deacetylation exert a dynamic balance that controls gene transcription. Although histone acetylation is associated with active transcription, histone deacetylation is associated with transcriptional repression. Hypoacetylated nucleosomes usually result in 
Table 1 HDAC inhibitors studied in Neuroblastoma

\begin{tabular}{|c|c|c|c|}
\hline Name & Alias & $\begin{array}{l}\text { Effective } \\
\text { in vivo }\end{array}$ & Reference \\
\hline $\begin{array}{l}\text { m-Carboxycinnamic acid bis- } \\
\text { hydroxamide }\end{array}$ & $\mathrm{CBHA}$ & + & $106-108$ \\
\hline $\begin{array}{l}\text { Suberoyl-3- } \\
\text { aminopyridineamide } \\
\text { hydroxamic acid }\end{array}$ & Pyroxamine & n.d. & 109 \\
\hline MS-275 & Entinostat & + & $110-113$ \\
\hline Sodium butyrate & $\mathrm{NaB}$ & n.d. & $114-119$ \\
\hline BL1521 & BL1521 & n.d. & $120-122$ \\
\hline Trichostatine A & TSA & + & $123-129$ \\
\hline Glycerin tributyrate & Tributyrin & n.d. & 85 \\
\hline M344 & M344 & n.d. & 111 \\
\hline HKI 46F08 & HKI 46F08 & n.d. & 130 \\
\hline $\begin{array}{l}\text { Helminthosporium } \\
\text { carbonum-toxin }\end{array}$ & HC-toxin & n.d. & 131 \\
\hline Romidepsin & Istodax & + & 132 \\
\hline C149 & C149 & n.d. & 133 \\
\hline LBH-589 & Panobinostat & + & 134,135 \\
\hline PCl-24781 & Abexinostat & + & 136,137 \\
\hline BRD8430 & BRD8430 & n.d. & 138 \\
\hline CAS 14513-15-6 & Cambinol & + & 76 \\
\hline Salermide & Salermide & n.d. & 77 \\
\hline PCl-35051 & PCl-35051 & + & 70,139 \\
\hline Tubacin & Tubacin & n.d. & 79,80 \\
\hline 1-Naphthohydroxamic acid & Cpd2 & + & 70 \\
\hline
\end{tabular}

n.d. not determined

tightly compacted chromatin, thereby restricting the access of transcription factors to their target DNA and leading to transcription repression (reviewed in ref. ${ }^{53}$ ). An alteration in this acetylation balance might result in the development of diseases, such as cancer.

The 18 histone deacetylases (HDAC) encoded in our genome can be classified based on their homology with yeast $\mathrm{HDAC}^{54}$ as follows: class I, which includes HDAC1, 2, 3 and 8; class II HDAC4, 5, 6, 7, 9 and 10; class III sirtuins (SIRT1-7); and class IV-only HDAC $11^{55}$.

All HDAC share a conserved histone deacetylase domain, but they vary in location, structure and expression patterns ${ }^{56}$. Classes I, II, and IV share homology in structure and sequence and require a zinc ion for their catalytic activity. Class III HDAC share no similarities with the other classes and require nicotinamide adenine dinucleotide $\left(\mathrm{NAD}^{+}\right)$for their activity ${ }^{57}$ (Fig. 2e).
Only two HDAC have been reported as associated with NB prognosis. Particularly, HDAC8 and HDAC10 were found to be overexpressed in high-risk $\mathrm{NB}$, and their inhibition resulted in reduced NB cell proliferation in vitro ${ }^{58,59}$ and in vivo ${ }^{60}$. Moreover, the inhibition of HDCA8 and 10 was found to increase doxorubicin sensitivity $^{58,61}$.

One of the most important genetic factors associated with NB outcome is the genomic amplification of the transcription factor $\mathrm{MYCN}$, a driver oncogene in $\mathrm{NB}$, which in turn regulates the expression of a myriad of genes associated with cell proliferation, survival and metastasis, among others. Selected HDAC have been shown to participate in a positive feedback loop with MYCN.

One of such examples was described for the Class III HDACs SIRT1. SIRT1 studies revealed that MYCN directly induced the transcription of SIRT1 and increased the stability of this oncogenic protein. Furthermore, pharmacologic inhibition of SIRT1 (cambinol) reduced tumorigenesis in a MYCN-driven neuroblastoma transgenic mouse model ${ }^{62}$.

Owing to the relevance of HDAC proteins in cancer, many inhibitors have been developed in recent decades. These inhibitors are classified depending on the targeted HDAC class. The first developed HDAC inhibitors (HDACi) were those targeting Classes I, II and IV and can be classified into six basic types depending on the structure of the inhibitor (reviewed in ref. ${ }^{63}$ ). In contrast, Class III HDAC are inhibited with derivatives of NAD ${ }^{64}$.

Multiple studies showed the therapeutic potential of HDACi in NB in preclinical studies (Table 1), but few reached clinical trials (Table 2).

One of the most studied HDACi in NB is valproic acid (VAP), which was discovered by B.S. Burton in $1882^{65}$. This inhibitor has higher but not exclusive selectivity to Class I HDAC. Initially, this compound was used to treat seizures, bipolar disorders or migraines. Different studies later showed that VAP inhibited HDAC proteins (reviewed in ref. ${ }^{66}$ ), thereby opening a door to cancer treatment.

When NB cells are treated with VAP, a strong inhibition of cell proliferation and induction of differentiation and apoptosis is observed ${ }^{67}, 68$. Other studies showed the therapeutic potential of VAP in combination with current therapies, such as ABT-510 (an angiogenic inhibitor) ${ }^{69}$ or with OGX- $011^{70}$ (inhibitor of clusterin), resulting in tumor growth impairment. However, in certain cases, VAP combination effects are subject to administration order. When VAP is combined with conventional chemotherapeutic agents, such as etoposide or cisplatin, these drugs must be administered before any other treatment ${ }^{71,72}$. 
Table 2 Current epigenetic drugs clinical trials in Neuroblastoma

\begin{tabular}{|c|c|c|c|c|}
\hline Name of the drug & Type of drug & Phase & Estate & Number \\
\hline \multirow[t]{2}{*}{ Decitabine } & \multirow[t]{2}{*}{ DNMT pan-inhibitor } & Phase I & Complete & NCT01241162 \\
\hline & & Phase I & Complete & NCT00075634 \\
\hline Genistein & DNMT pan-inhibitor & Phase II & Recruiting & NCT02624388 \\
\hline \multirow[t]{6}{*}{ Vorinostat } & \multirow[t]{6}{*}{ HDACiclass I and II inhibitor } & Phase I & Complete & NCT00217412 \\
\hline & & Phase I & Complete & NCT01132911 \\
\hline & & Phase ॥ & Ongoing but not recruiting & NCT02035137 \\
\hline & & Phase I & Recruiting & NCT02559778 \\
\hline & & Phase I & Complete & NCT01019850 \\
\hline & & Phase I & Complete & NCT01208454 \\
\hline VAP & HDACiclass I and II inhibitor & Phase I & Ccomplete & NCT01204450 \\
\hline $4-P B$ & HDACipan-inhibitor & Phase I & Complete & NCT00001565 \\
\hline GSK525762 & iBET & Phase I & Recruiting & NCT01587703 \\
\hline
\end{tabular}

Another well-studied HDACi in NB is vorinostat (also known as SAHA). Vorinostat is a selective class I and II HDACi and is currently in use in multiple clinical trials in NB. Treatment of NB cells with vorinostat resulted in cell cycle arrest in G2/M phase followed by the activation of the intrinsic apoptotic pathway ${ }^{73}$. Vorinostat was also shown to impair VEGF secretion by NB cells, thereby suggesting a potential antiangiogenic effect ${ }^{74}$.

Vorinostat has also been shown to potentiate the antitumor activity of different drugs, such as flavopiridol (a pan-Cdk inhibitor) ${ }^{75}$ and fenretinide (a synthetic retinoid $)^{76}$, and therapies, such as radiotherapy ${ }^{77,78}$.

The latest HDACi to reach clinical trials was 4PB (4phenylbutyrate), which is also selective for HDAC class I and II. In 1998, Pelidis et al. described the effectiveness of $4 \mathrm{~PB}$ in $\mathrm{NB}$ for the first time and demonstrated that $4 \mathrm{~PB}$ reduced proliferation and induced differentiation of $\mathrm{NB}$ cell lines. Moreover, 4PB demonstrated additive cytotoxic effects when administered with the chemotherapeutic drug vincristine ${ }^{79}$. Concurring with these results, Tang et al. showed that $4 \mathrm{~PB}$ induced the expression of several genes associated with favorable outcome (i.e., EPHB6, EFNB2, EFNB3, NTRK1, and CD44) and impaired tumor growth and metastasis in vitro and in vivo ${ }^{80}$.

\section{Histone phosphorylation}

Histone phosphorylation is widely known to be involved in chromatin condensation during cell division and apoptosis and also acts as an important signal for DNA damage response. These are transient processes that do not produce stable and heritable changes in gene expression. However, phosphorylation of certain histone residues has also been directly related to transcriptional regulation control. In fact, many phosphorylated sites act by crosstalk with other histone modifications, such as methylation or acetylation. (reviewed in the literature ${ }^{81,82}$ ).

Phosphorylation and dephosphorylation of histones are performed by kinases and phosphatases, respectively. Most of these enzymes are not histone specific. For example, Aurora B kinase is known to phosphorylate histone $\mathrm{H} 3$ on serine 10 to induce chromosome condensation in the early phases of cell division, which is essential for cell cycle progression ${ }^{83}$. Aurora B kinase has been found as a potential target for NB treatment, and its inhibition with barasertib promotes arrest in the G2/M phase followed by apoptosis in vitro and in vivo 84,85 . Selected histone phosphatases have also been reported to play a role in NB biology. EYA1, which dephosphorylates the tyrosine 142 of histone $\mathrm{H} 2 \mathrm{AX}$, is downregulated in the advanced stages of $\mathrm{NB}^{86}$. Phosphatase PP2A has also been observed to exert tumor suppressive effects on NB cells ${ }^{87}$.

Although many kinases and phosphatases able to modify histone residues are under study as targets for NB treatment, the impact of histone phosphorylation in itself on NB progression is still not well characterized and should be investigated further.

Histone modifiers are by far the largest family of epigenetic regulators. Structural similarities have paved the way for the design of pan-inhibitors, such as those developed for HDAC. Despite a growing body of evidence showing therapeutic potential in preclinical studies, only modest results have been observed in clinical trials to date. A better understanding of the tumor-specific dependency on each of these epigenetic regulators might lead to the development of additional targetspecific inhibitors and better patient selection. 
Table 3 Potential new epigenetic targets in neuroblastoma at early preclinical research studies

\begin{tabular}{llll}
\hline Family/Class & Gene symbol & Prognostic value & Function \\
\hline HMT / PKMT & NSD1 & Low is worse & Cell proliferation \\
HMT / PKMT & WHSC1 & High is worse & n.d. \\
HMT / PKMT & EZH2 & High is worse & Cell differentiation and gene expression regulator \\
HMT / PRMT & PRMT5 & High is worse & Cell proliferation / survival \\
HDM / KDM1 & KDM1A & High is worse & Cell proliferation / invasion \\
& & & \\
HDM / JHDM & JMJD1A & n.d. & Migration / invasion \\
HDM / JHDM & JARID1B & High is worse & Invasion / chemoresistance \\
HDAC / Class I & HDAC2 & n.d. & Increased proliferation / survival \\
HDAC / Class I & HDAC5 & n.d. & Block differentiation / induce proliferation \\
HDAC / Class II & HDAC6 & n.d. & Regulates cell survival \\
HDAC / Class III & SIRT2 & n.d. & Increased proliferation \\
HDAC / Class IV & HDAC11 & n.d. & Regulates cell survival \\
\hline
\end{tabular}

$H M T$ histone methyl-transferase, n.d. not determined ${ }^{144-151}$

\section{Chromatin readers}

To translate the pattern of histone modifications into a functional phenotype, these modifications must be recognized by proteins known as "readers". These readers are bromodomain (BRD), chromodomain and tudordomain containing proteins, which recognize histone marks and recruit other proteins required to start or inhibit transcription. Bromodomain-containing proteins are capable of recognizing the acetylation of histones, whereas chromodomains and tudor-domains recognize methylated histones ${ }^{88,89}$.

BRD-containing proteins are highly conserved throughout evolution and can perform various functions, such as histone acetylation, chromatin remodeling and transcriptional activation ${ }^{90}$. The human homolog of the drosophila gene Brahma $(\mathrm{Brm})^{91}$ was the first of 61 human BRD to be described, a subset of 46 BRDcontaining proteins ${ }^{92}$. All known BRD have a central hydrophobic pocket with a highly conserved asparagine residue responsible for the binding to the acetylated lysines of histones ${ }^{93}$ (Fig. 2f).

Only one study to date has demonstrated the correlation of a BRD-containing protein and NB outcome. BPTF was found to be amplified in 55\% of NB cases due to gain of the 17q24.3 locus $^{94}$. In silico analysis of mRNA expression data sets in NB [EGEOD-3960, Fig. 3] shows that at least $15 \mathrm{BRD}$-containing proteins are differentially expressed in patients with advanced disease and poor prognosis (10 were upregulated, 5 were downregulated), thereby suggesting that they could be new potential therapeutic targets for NB.

The crystallization of the BRD structure and the feasibility of designing small molecules to target this domain placed the BRD inhibitors in the spotlight as new therapeutic targets for cancer. In 2010, two small-molecule inhibitors against BET-bromodomains (a family of BRD known as bromodomain and extra-terminal domain, which consists of four different proteins) were described by two independent groups (JQ1 and I-BET ${ }^{95,96}$ ) with high affinity for BRD2, BRD3 and BRD4. Both compounds showed that BRD inhibition resulted in antitumor effects in mixed lineage leukemia ${ }^{97}$, multiple myeloma ${ }^{98}$, or lung adenocarcinomas $^{99}$.

The therapeutic potential of BRD inhibition in NB was first analyzed by Puissant et al. Treatment of NB cells with the BET inhibitor (iBET) JQ1 resulted in a reduction in MYCN levels, reduced cell growth and induction of apoptosis in vitro and in vivo ${ }^{100,}{ }^{101}$. The JQ1 inhibitor also showed synergistic effects when combined with the HDACi panobinostat. This drug combination showed reduced MYCN protein expression and impaired tumor growth in vivo ${ }^{102}$.

Recently, another BRD inhibitor (i.e., OTX015) was tested in NB. Administration of OTX015 produced a reduction in MYCN expression and loss of interaction of MYCN with the promoter of their target genes. Furthermore, BRD4 was also shown to be preferentially displaced from DNA super-enhancers regulated by $\mathrm{MYCN}^{103}$.

\section{Conclusions and future perspectives}

Classically, pediatric oncology has mirrored the therapeutic strategies of adult oncology, and epigenetic therapies are not an exception. In addition to considering epigenetic modifications as diagnostic or prognostic tools, a large proportion of clinical trials $(\sim 40 \%)$ focus on 
evaluating the therapeutic potential of DNMTi followed by HDACi $(\sim 10 \%)$, either as single agents or in combination with standard therapies. Therefore, a long list of potential new epigenetic targets remains to be explored. In particular, in NB, only three HDACi, two DNMTi and one iBET compounds have reached clinical trials, and of these, only two inhibitors have reached phase II: genistein and vorinostat (Table 2).

The low number of active clinical trials, despite preclinical evidence of the role of epigenetic regulators in NB, underlines the need for advanced preclinical studies in new therapeutic targets (Table 3) and the development of new compounds, probably more specific versions, which should be more effective at tolerable doses and with fewer side effects. The compounds that reached clinical trials have specificity for more than one target of the same family and are referred to as pan-inhibitors. Presumably, the development of more specific compounds (instead of pan-inhibitors) against chromatin remodeler proteins found to be altered in NB will be more cancer-specific and have potentially fewer side effects. Nevertheless, most of these epigenetic regulators are poorly characterized with few crystallized structures. Therefore, design and development of new small molecules remains a great challenge. Additional efforts must be invested in the definition of these structures to create better inhibitors for development of future treatments. Alternatively, blocking of protein-protein interactions or siRNA-mediated gene silencing could be considered.

\section{Acknowledgements \\ This work was supported by the Instituto de Salud Carlos III (CPII16/00006, PI17/00564, RD12/0036/0016) and co-financed by the European Regional Development Fund (ERDF), Generalitat de Catalunya 2014-SGR-660, and Asociación Acunapatata. The authors thank Ms. Christine O'Hara for English language correction and the members of the Group of Translational Research in Child and Adolescent Cancer for helpful suggestions and discussion. The authors apologize to their colleagues whose work could not be cited in this paper due to space limitations. The authors have no financial relationships relevant to this article to disclose.}

\section{Conflict of interest}

The authors declare that they have no conflict of interest.

\section{Publisher's note}

Springer Nature remains neutral with regard to jurisdictional claims in published maps and institutional affiliations.

Received: 7 September 2017 Revised: 13 January 2018 Accepted: 31 January 2018.

Published online: 27 April 2018

\footnotetext{
References

1. DeVita, V. T. \& Rosenberg, S. A. Two hundred years of cancer research. N. Engl. J. Med 23, 2207-2214 (2012).

2. Khamisipour, G., Jadidi-Niaragh, F., Jahromi, A. S., Zandi, K. \& Hojjat-Farsangi, M. Mechanisms of tumor cell resistance to the current targeted-therapy agents. Tumor Biol. 37, 10021-10039 (2016).
}

3. Shi, V. J., Levy, L. L. \& Choi, J. N. Cutaneous manifestations of nontargeted and targeted chemotherapies. Semin Oncol. 43, 419-425 (2016).

4. Ezoe, S. Secondary leukemia associated with the anti-cancer agent, etoposide, a topoisomerase II inhibitor. Int J. Environ. Res. Public Health 9, 2444-2453 (2012).

5. Pàez-Ribes, M., Allen, E., Hudock, J., Takeda, T., Okuyama, H. \& Viñals, F. et al. Antiangiogenic therapy elicits malignant progression of tumors to increased local invasion and distant metastasis. Cancer Cell 15, 220-231 (2009).

6. Zinzani, P. L., Rigacci, L., Cox, M. C., Devizzi, L., Fabbri, A. \& Zaja, F. et al. The efficacy of lenalidomide combination therapy in heavily pretreated nonHodgkin lymphoma patients: an Italian observational, multicenter, retrospective study. Leuk. Lymphoma 58, 226-229 (2017).

7. Kozyreva, V. K., Kiseleva, A. A., Ice, R. J., Jones, B. C., Loskutov, Y. V. \& Matalkah, F. et al. Combination of Eribulin and Aurora A Inhibitor MLN8237 prevents metastatic colonization and induces cytotoxic autophagy in breast cancer. Mol. Cancer Ther. 15, 1809-1822 (2016).

8. Zou, H., Li, L., Garcia Carcedo, I., Xu, Z. P., Monteiro, M. \& Gu, W. Synergistic inhibition of colon cancer cell growth with nanoemulsion-loaded paclitaxel and PI3K/mTOR dual inhibitor BEZ235 through apoptosis. Int J. Nanomed. 11, 1947-1958 (2016).

9. Berger, S. L., Kouzarides, T., Shiekhattar, R. \& Shilatifard, A. An operational definition of epigenetics. Genes Dev. 23, 781-783 (2009).

10. Chuang, J. C., Warner, S. L., Vollmer, D., Vankayalapati, H., Redkar, S. \& Bearss, D. J. et al. S110, a 5-Aza-2'-deoxycytidine-containing dinucleotide, is an effective DNA methylation inhibitor in vivo and can reduce tumor growth. Mol. Cancer Ther. 9, 1443-1450 (2010).

11. Meng, C. F., Zhu, X. J., Peng, G. \& Dai, D. Q. Re-expression of methylationinduced tumor suppressor gene silencing is associated with the state of histone modification in gastric cancer cell lines. World J. Gastroenterol. 13, 6166-6171 (2007).

12. Olsen, E. M., Petersen, J., Skovgaard, A. M., Weile, B., Jørgensen, T. \& Wright, C. $M$. Failure to thrive: the prevalence and concurrence of anthropometric criteria in a general infant population. Arch. Dis. Child 92, 109-114 (2007).

13. Fenaux, P., Mufti, G. J., Hellstrom-Lindberg, E., Santini, V., Finelli, C. \& Giagounidis, A. et al. Efficacy of azacitidine compared with that of conventional care regimens in the treatment of higher-risk myelodysplastic syndromes: a randomised, open-label, phase III study. Lancet Oncol. 10, 223-232 (2009).

14. Piekarz, R. L., Frye, R., Turner, M., Wright, J. J., Allen, S. L. \& Kirschbaum, M. H. et al. Phase II multi-institutional trial of the histone deacetylase inhibitor romidepsin as monotherapy for patients with cutaneous T-cell lymphoma. J. Clin. Oncol. 27, 5410-5417 (2009).

15. Tsai, H. C., Li, H., Van Neste, L., Cai, Y., Robert, C. \& Rassool, F. V. et al. Transient low doses of DNA-demethylating agents exert durable antitumor effects on hematological and epithelial tumor cells. Cancer Cell 21, 430-446 (2012).

16. Grishina, O., Schmoor, C., Döhner, K., Hackanson, B., Lubrich, B. \& May, A. M. et al. DECIDER: prospective randomized multicenter phase II trial of low-dose decitabine (DAC) administered alone or in combination with the histone deacetylase inhibitor valproic acid (VPA) and all-trans retinoic acid (ATRA) in patients $>60$ years with acute myeloid leukemia who are ineligible for induction chemotherapy. BMC Cancer 15, 430 (2015).

17. Berenguer-Daizé, C., Astorgues-Xerri, L., Odore, E., Cayol, M., Cvitkovic, E. \& Noel, K. et al. OTX015 (MK-8628), a novel BET inhibitor, displays in vitro and in vivo antitumor effects alone and in combination with conventional therapies in glioblastoma models. Int. J. Cancer 139, 2047-2055 (2016).

18. Maris, J. M. Recent advances in neuroblastoma. N. Engl. J. Med 362, 2202-2211 (2010)

19. Cohn, S. L., Pearson, A. D. J., London, W. B., Monclair, T., Ambros, P. F. \& Brodeur, G. M. et al. The International Neuroblastoma Risk Group (INRG) classification system: an INRG Task Force report. J. Clin. Oncol. 27, 289-297 (2009).

20. Cedar, H. \& Bergman, Y. Linking DNA methylation and histone modification: patterns and paradigms. Nat. Rev. Genet 10, 295-304 (2009).

21. Jurkowska, R. Z., Jurkowski, T. P. \& Jeltsch, A. Structure and function of mammalian DNA methyltransferases. Chembiochem 12, 206-222 (2011).

22. Craddock, V. M. \& Magee, P. N. Analysis of bases of rat-liver nucleic acids after administration of the carcinogen dimethylnitrosamine. Biochem J. 100, 724-732 (1966).

23. Silber, R., Berman, E., Goldstein, B., Stein, H., Farnham, G. \& Bertino, J. R. Methylation of nucleic acids in normal and leukemic leukocytes. Biochim Biophys. Acta 123, 638-640 (1966). 
24. Qiu, Y. Y., Mirkin, B. L. \& Dwivedi, R. S. Inhibition of DNA methyltransferase reverses cisplatin induced drug resistance in murine neuroblastoma cells. Cancer Detect. Prev. 29, 456-463 (2005).

25. Ostler, K. R., Yang, Q., Looney, T. J., Zhang, L., Vasanthakumar, A. \& Tian, Y. et al Truncated DNMT3B isoform DNMT3B7 suppresses growth, induces differentiation, and alters DNA methylation in human neuroblastoma. Cancer Res 72, 4714-4723 (2012).

26. Gómez, S., Castellano, G., Mayol, G., Suñol, M., Queiros, A. \& Bibikova, M. et al. DNA methylation fingerprint of neuroblastoma reveals new biological and clinical insights. Epigenomics 7, 1137-1153 (2015).

27. Bartolucci, S., Estenoz, M., Longo, A., Santoro, B., Momparler, R. L. \& Rossi, M. et al. 5-Aza-2'-deoxycytidine as inducer of differentiation and growth inhibition in mouse neuroblastoma cells. Cell Differ. Dev. 27, 47-55 (1989).

28. Carpinelli, P., Granata, F., Augusti-Tocco, G., Rossi, M. \& Bartolucci, S. Antiproliferative effects and DNA hypomethylation by 5-aza-2'-deoxycytidine in human neuroblastoma cell lines. Anticancer Drugs 4, 629-635 (1993).

29. Charlet, J., Schnekenburger, M., Brown, K. W. \& Diederich, M. DNA demethylation increases sensitivity of neuroblastoma cells to chemotherapeutic drugs. Biochem. Pharmacol. 83, 858-865 (2012).

30. George, R. E., Lahti, J. M., Adamson, P. C., Zhu, K., Finkelstein, D. \& Ingle, A. M. et al. Phase I study of decitabine with doxorubicin and cyclophosphamide in children with neuroblastoma and other solid tumors: a children's oncology group study. Pediatr. Blood Cancer 55, 629-638 (2010).

31. Penter, L., Maier, B., Frede, U., Hackner, B., Carell, T. \& Hagemeier, C. et al. A rapid screening system evaluates novel inhibitors of DNA methylation and suggests F-box proteins as potential therapeutic targets for high-risk neuroblastoma. Target Oncol. 10, 523-533 (2015).

32. Yi, X., Jiang, X. J., Li, X. Y. \& Jiang, D. S. Histone methyltransferases: Novel targets for tumor and developmental defects. Am. J. Transl. Res. 7, 2159-2175 (2015).

33. Morera, L., Lübbert, M. \& Jung, M. Targeting histone methyltransferases and demethylases in clinical trials for cancer therapy. Clin. Epigenetics 8, 57 (2016).

34. Michalak, E. M. \& Visvader, J. E. Dysregulation of histone methyltransferases in breast cancer-opportunities for new targeted therapies? Mol. Oncol. 10, 1497-1515 (2016).

35. Copeland, R. A., Solomon, M. E. \& Richon, V. M. Protein methyltransferases as a target class for drug discovery. Nat. Rev. Drug Discov. 8, 724-732 (2009).

36. Schapira, M. Structural chemistry of human SET domain protein methyltransferases. Curr. Chem. Genom. 5, 85-94 (2011).

37. Spannhoff, A., Hauser, A. T., Heinke, R., Sippl, W. \& Jung, M. The emerging therapeutic potential of histone methyltransferase and demethylase inhibitors. ChemMedChem 4, 1568-1582 (2009).

38. Greer, E. L. \& Shi, Y. Histone methylation: a dynamic mark in health, disease and inheritance. Nat. Rev. Genet. 13, 343-357 (2012).

39. Lu, Z., Tian, Y., Salwen, H. R., Chlenski, A., Godley, L. A. \& Raj, J. U. et al. Histonelysine methyltransferase EHMT2 is involved in proliferation, apoptosis, cell invasion, and DNA methylation of human neuroblastoma cells. Anticancer Drugs 24, 484-493 (2013).

40. Ke, X. X., Zhang, D., Zhu, S., Xia, Q., Xiang, Z. \& Cui, H. Inhibition of H3K9 methyltransferase G9A repressed cell proliferation and induced autophagy in neuroblastoma. PLoS One 9, e106962 (2014).

41. Shi, Y., Lan, F., Matson, C., Mulligan, P., Whetstine, J. R. \& Cole, P. A. et al. Histone demethylation mediated by the nuclear amine oxidase homolog LSD1. Cell 119, 941-953 (2004).

42. Chang, B., Chen, Y., Zhao, Y. \& Bruick, R. K. JMJD6 is a histone arginine demethylase. Science 318, 444-447 (2007).

43. Althoff, K., Beckers, A., Odersky, A., Mestdagh, P., Köster, J. \& Bray, I. M. et al. MiR-137 functions as a tumor suppressor in neuroblastoma by downregulating KDM1A. Int. J. Cancer 133, 1064-1073 (2013).

44. Yang, H., Li, Q., Zhao, W., Yuan, D., Zhao, H. \& Zhou, Y. MiR-329 suppresses the growth and motility of neuroblastoma by targeting KDM1A. FEBS Lett. $\mathbf{5 8 8}$ 192-197 (2014).

45. Yang, J., Altahan, A. M., Hu, D., Wang, Y., Cheng, P. H. \& Morton, C. L. et al. The role of histone demethylase KDM4B in Myc signaling in neuroblastoma. J. Natl Cancer Inst. 107, 1-9 (2015).

46. Sun, X.-J., Man, N., Tan, Y., Nimer, S. D. \& Wang, L. The role of histone acetyltransferases in normal and malignant hematopoiesis. Front. Oncol. 5, 108 (2015).

47. Brownell, J. E., Zhou, J., Ranalli, T., Kobayashi, R., Edmondson, D. G. \& Roth, S. Y. et al. Tetrahymena histone acetyltransferase A: a homolog to yeast Gcn5p linking histone acetylation to gene activation. Cell 84, 843-851 (1996).
48. Taunton, J., Hassig, C. A. \& Schreiber, S. L. A mammalian histone deacetylase related to the yeast transcriptional regulator Rpd3p. Science $\mathbf{2 7 2}$, 408-411 (1996).

49. Glozak, M. A., Sengupta, N., Zhang, X. \& Seto, E. Acetylation and deacetylation of non-histone proteins. Gene 363, 15-23 (2005).

50. Haery, L., Thompson, R. C. \& Gilmore, T. D. Histone acetyltransferases and histone deacetylases in B- and T-cell development, physiology and malignancy. Genes Cancer 6, 184-213 (2015).

51. Gajer, J. M., Furdas, S. D., Gründer, A., Gothwal, M., Heinicke, U. \& Keller, K. et al. Histone acetyltransferase inhibitors block neuroblastoma cell growth in vivo. Oncogenesis 4, e137 (2015).

52. Secci, D., Carradori, S., Bizzarri, B., Bolasco, A., Ballario, P. \& Patramani, Z. et al. Synthesis of a novel series of thiazole-based histone acetyltransferase inhibitors. Bioorg. Med. Chem. 22, 1680-1689 (2014).

53. Lin, H. Y., Chen, C. S., Lin, S. P., Weng, J. R. \& Chen, C. S. Targeting histone deacetylase in cancer therapy. Med. Res. Rev. 26, 397-413 (2006).

54. Thiagalingam, S., Cheng, K.-H., Lee, H. J., Mineva, N., Thiagalingam, A. \& Ponte, J. F. Histone deacetylases: unique players in shaping the epigenetic histone code. Ann. N. Y Acad. Sci. 983, 84-100 (2003).

55. Damaskos, C., Karatzas, T., Nikolidakis, L., Kostakis, I. D., Karamaroudis, S. \& Boutsikos, G. et al. Histone deacetylase (HDAC) inhibitors: current evidence for therapeutic activities in pancreatic cancer. Anticancer Res. 35, 3129-3135 (2015).

56. Ummarino, D., Li, Y. \& Zeng, L. Roles of histone deacetylases in angiogenic cellular processes. Curr. Angiogenes 2, 60-66 (2013).

57. de Ruijter, A. J. M., van Gennip, A. H., Caron, H. N., Kemp, S. \& van Kuilenburg, A. B. Histone deacetylases (HDACs): characterization of the classical HDAC family. Biochem. J. 370, 737-749 (2003).

58. Oehme, I., Deubzer, H. E., Lodrini, M., Milde, T. \& Witt, O. Targeting of HDAC8 and investigational inhibitors in neuroblastoma. Expert Opin. Investig. Drugs 18, 1605-1617 (2009).

59. Oehme, I., Linke, J. P., Böck, B. C., Milde, T., Lodrini, M. \& Hartenstein, B. et al. Histone deacetylase 10 promotes autophagy-mediated cell survival. Proc. Natl Acad. Sci. USA 110, E2592-E2601 (2013).

60. Rettig, I., Koeneke, E., Trippel, F., Mueller, W. C., Burhenne, J. \& Kopp-Schneider, A. et al. Selective inhibition of HDAC8 decreases neuroblastoma growth in vitro and in vivo and enhances retinoic acid-mediated differentiation. Cell Death Dis. 6, e1657 (2015).

61. Zhao, G., Wang, G., Bai, H., Li, T., Gong, F. \& Yang, H. et al. Targeted inhibition of HDAC8 increases the doxorubicin sensitivity of neuroblastoma cells via up regulation of miR-137. Eur. J. Pharmacol. 802, 20-26 (2017).

62. Marshall, G. M., Liu, P. Y., Gherardi, S., Scarlett, C. J., Bedalov, A. \& Xu, N. et al. SIRT1 promotes N-Myc oncogenesis through a positive feedback loop involving the effects of MKP3 and ERK on N-Myc protein stability. PLoS Genet. 7, e1002135 (2011).

63. Drummond, D., Noble, C., Kirpotin, D. \& Guo, Z. Clinical development of histone deacetylase inhibitors as anticancer agents. Annu Rev. Pharmacol. Toxicol. 45, 495-528 (2005).

64. Porcu, M. \& Chiarugi, A. The emerging therapeutic potential of sirtuininteracting drugs: from cell death to lifespan extension. Trends Pharmacol. Sci. 26, 94-103 (2005).

65. Burton, B. S. On the propyl derivatives and decomposition products of ethylacetate. Am. Chem. J. 3, 385-395 (1882)

66. Göttlicher, M. \& Satelite Symposium, V. Meet-the-professor sessions I and II, main sessions I-IX. Ann. Hematol. 83, S59-S137 (2004).

67. Rocchi, P., Tonelli, R., Camerin, C., Purgato, S., Fronza, R. \& Bianucci, F. et al. p21Waf1/Cip1 is a common target induced by short-chain fatty acid HDAC inhibitors (valproic acid, tributyrin and sodium butyrate) in neuroblastoma cells. Oncol. Rep. 13, 1139-1144 (2005).

68. Stockhausen, M.-T., Sjölund, J., Manetopoulos, C. \& Axelson, H. Effects of the histone deacetylase inhibitor valproic acid on Notch signalling in human neuroblastoma cells. Br. J. Cancer 92, 751-759 (2005).

69. Yang, Q., Tian, Y., Liu, S., Zeine, R., Chlenski, A. \& Salwen, H. R. et al. Thrombospondin-1 peptide ABT-510 combined with valproic acid is an effective antiangiogenesis strategy in neuroblastoma. Cancer Res 67, 1716-1724 (2007).

70. Liu, T., Liu, P. Y., Tee, A. E. L., Haber, M., Norris, M. D. \& Gleave, M. E. et al. Overexpression of clusterin is a resistance factor to the anti-cancer effect of histone deacetylase inhibitors. Eur. J. Cancer 45, 1846-1854 (2009).

71. Groh, T., Hrabeta, J., Khalil, M., Doktorova, H., Eckschlager, T. \& Stiborova, M. The synergistic effects of DNA-damaging drugs cisplatin and etoposide with 
a histone deacetylase inhibitor valproate in high-risk neuroblastoma cells. Int J. Oncol. 47, 343-352 (2015).

72. Groh, T., Hrabeta, J., Poljakova, J., Eckschlager, T. \& Stiborova, M. Impact of histone deacetylase inhibitor valproic acid on the anticancer effect of etoposide on neuroblastoma cells. Neuro Endocrinol. Lett. 33, 16-24 (2012).

73. De los Santos, M., Zambrano, A. \& Aranda, A. Combined effects of retinoic acid and histone deacetylase inhibitors on human neuroblastoma SH-SY5Y cells. Mol. Cancer Ther. 6, 1425-1432 (2007).

74. Mühlethaler-Mottet, A., Meier, R., Flahaut, M., Bourloud, K. B., Nardou, K. \& Joseph, J.-M. et al. Complex molecular mechanisms cooperate to mediate histone deacetylase inhibitors anti-tumour activity in neuroblastoma cells. Mol. Cancer 7, 55 (2008).

75. Huang, J.-M., Sheard, M. A., Ji, L., Sposto, R. \& Keshelava, N. Combination of vorinostat and flavopiridol is selectively cytotoxic to multidrug-resistant neuroblastoma cell lines with mutant TP53. Mol. Cancer Ther. 9, 3289-3301 (2010).

76. Cheung, B. B., Tan, O., Koach, J., Liu, B., Shum, M. S. Y. \& Carter, D. R. et al. Thymosin- $\beta 4$ is a determinant of drug sensitivity for Fenretinide and Vorinostat combination therapy in neuroblastoma. Mol. Oncol. 9, 1484-1500 (2015).

77. Mueller, S., Yang, X., Sottero, T. L., Gragg, A., Prasad, G. \& Polley, M. Y. et al. Cooperation of the HDAC inhibitor vorinostat and radiation in metastatic neuroblastoma: efficacy and underlying mechanisms. Cancer Lett. 306, 223-229 (2011).

78. More, S. S., Itsara, M., Yang, X., Geier, E. G., Tadano, M. K. \& Seo, Y. et al. Vorinostat increases expression of functional norepinephrine transporter in neuroblastoma in vitro and in vivo model systems. Clin. Cancer Res. 17, 2339-2349 (2011).

79. Pelidis, M. A., Carducci, M. A. \& Simons, J. W. Cytotoxic effects of sodium phenylbutyrate on human neuroblastoma cell lines. Int J. Oncol. 12, 889-893 (1998).

80. Tang, X. X., Robinson, M. E., Riceberg, J. S., Kim, D. Y., Kung, B. \& Titus, T. B. et al. Favorable neuroblastoma genes and molecular therapeutics of neuroblastoma. Clin. Cancer Res. 10, 5837-5844 (2004).

81. Baek, S. H. When signaling kinases meet histones and histone modifiers in the nucleus. Mol. Cell 42, 274-284 (2011).

82. Rossetto, D., Awakumov, N. \& Côté, J. Histone phosphorylation: a chromatin modification involved in diverse nuclear events. Epigenetics 7, 1098-1108 (2012)

83. Zeitlin, S. G., Shelby, R. D. \& Sullivan, K. F. CENP-A is phosphorylated by Aurora $\mathrm{B}$ kinase and plays an unexpected role in completion of cytokinesis. J. Cell Biol. 155, 1147-1158 (2001).

84. Morozova, O., Vojvodic, M., Grinshtein, N., Hansford, L. M., Blakely, K. M. \& Maslova, A. et al. System-level analysis of neuroblastoma tumor-initiating cells implicates AURKB as a novel drug target for neuroblastoma. Clin. Cancer Res. 16, 4572-4582 (2010).

85. Bogen, D., Wei, J. S., Azorsa, D. O., Ormanoglu, P., Buehler, E. \& Guha, R. et al. Aurora B kinase is a potent and selective target in MYCN-driven neuroblastoma. Oncotarget 6, 35247-35262 (2015).

86. Hansen, J. N., Lotta, L. T., Eberhardt, A., Schor, N. F. \& Li, X. EYA1 expression and subcellular localization in neuroblastoma and its association with prognostic markers. J. Cancer Res. Ther. 4, 11-18 (2016).

87. Khanna, A., Kauko, O., Bockelman, C., Laine, A., Schreck, I. \& Partanen, J. I. et al. Chk1 targeting reactivates PP2A tumor suppressor activity in cancer cells. Cancer Res. 73, 6757-6769 (2013).

88. Jacobs, S. A. \& Khorasanizadeh, S. Structure of HP1 chromodomain bound to a lysine 9-methylated histone H3 tail. Science 295, 2080-2083 (2002).

89. Huang, Y., Fang, J., Bedford, M. T., Zhang, Y. \& Xu, R. M. Recognition of histone $\mathrm{H} 3$ lysine-4 Methylation by the double tudor domain of JMJD2A. Science 312, 748-751 (2006).

90. Ntranos, A. \& Casaccia, P. Bromodomains: translating the words of lysine acetylation into myelin injury and repair. Neurosci. Lett. 625, 4-10 (2016).

91. Tamkun, J. W., Deuring, R., Scott, M. P., Kissinger, M., Pattatucci, A. M. \& Kaufman, T. C. et al. brahma: a regulator of Drosophila homeotic genes structurally related to the yeast transcriptional activator SNF2/SWI2. Cell 68, 561-572 (1992).

92. Filippakopoulos, P. \& Knapp, S. The bromodomain interaction module. FEBS Lett. 586, 2692-2704 (2012).

93. Zhou, M.-M., Dhalluin, C., Carlson, J. E., Zeng, L., He, C. \& Aggarwal, A. K. et al. Structure and ligand of a histone acetyltransferase bromodomain. Nature 399, 491-496 (1999).
94. Buganim, Y., Goldstein, I., Lipson, D., Milyavsky, M., Polak-Charcon, S. \& Mardoukh, $C$. et al. A novel translocation breakpoint within the BPTF gene is associated with a pre-malignant phenotype. PLoS One 5, e9657 (2010).

95. Filippakopoulos, P., Qi, J., Picaud, S., Shen, Y., Smith, W. B. \& Fedorov, O. et al. Selective inhibition of BET bromodomains. Nature 468, 1067-1073 (2010).

96. Nicodeme, E., Jeffrey, K. L., Schaefer, U., Beinke, S., Dewell, S. \& Chung, C.-W. et al. Suppression of inflammation by a synthetic histone mimic. Nature $\mathbf{4 6 8}$, 1119-1123 (2010).

97. Dawson, M. A., Prinjha, R. K., Dittmann, A., Giotopoulos, G., Bantscheff, M. \& Chan, W.-I. et al. Inhibition of BET recruitment to chromatin as an effective treatment for MLL-fusion leukaemia. Nature 478, 529-533 (2011).

98. Delmore, J. E., Issa, G. C., Lemieux, M. E., Rahl, P. B., Shi, J. \& Jacobs, H. M. et al. BET bromodomain inhibition as a therapeutic strategy to target c-Myc. Cell 146, 904-917 (2011).

99. Lockwood, W. W., Zejnullahu, K., Bradner, J. E. \& Varmus, H. Sensitivity of human lung adenocarcinoma cell lines to targeted inhibition of BET epigenetic signaling proteins. Proc. Natl Acad. Sci. USA 109, 19408-19413 (2012).

100. Puissant, A., Frumm, S. M., Alexe, G., Bassil, C. F., Qi, J. \& Chanthery, Y. H. et al. Targeting MYCN in neuroblastoma by BET bromodomain inhibition. Cancer Discov. 3, 309-323 (2013).

101. Lee, S., Rellinger, E. J., Kim, K. W., Craig, B. T., Romain, C. V. \& Qiao, J. et al. Bromodomain and extraterminal inhibition blocks tumor progression and promotes differentiation in neuroblastoma. Surgery 158, 819-826 (2015).

102. Shahbazi, J., Liu, P. Y., Atmadibrata, B., Bradner, J. E., Marshall, G. M. \& Lock, R. B. et al. The bromodomain inhibitor jq1 and the histone deacetylase inhibitor panobinostat synergistically reduce n-myc expression and induce anticancer effects. Clin. Cancer Res. 22, 2534-2544 (2016).

103. Henssen, A., Althoff, K., Odersky, A., Beckers, A., Koche, R. \& Speleman, F. et al. Targeting MYCN-driven transcription by BET-bromodomain inhibition. Clin. Cancer Res. 22, 2470-2781 (2016).

104. Consortium, U. UniProt: the universal protein knowledgebase. Nucleic Acids Res. 45, D158-D169 (2017).

105. Finn, R. D., Attwood, T. K., Babbitt, P. C., Bateman, A., Bork, P. \& Bridge, A. J. et al. InterPro in 2017-beyond protein family and domain annotations. Nucleic Acids Res. 45, D190-D199 (2017).

106. Subramanian, C., Opipari, A. W., Bian, X., Castle, V. P. \& Kwok, R. P. Ku70 acetylation mediates neuroblastoma cell death induced by histone deacetylase inhibitors. Proc. Natl Acad. Sci. USA 102, 4842-4847 (2005).

107. Mühlethaler-Mottet, A., Flahaut, M., Bourloud, K. B., Auderset, K., Meier, R. \& Joseph, J.-M. et al. Histone deacetylase inhibitors strongly sensitise neuroblastoma cells to TRAlL-induced apoptosis by a caspases-dependent increase of the pro- to anti-apoptotic proteins ratio. BMC Cancer $\mathbf{6}, 214$ (2006).

108. De los Santos, M., Zambrano, A. \& Aranda, A. Combined effects of retinoic acid and histone deacetylase inhibitors on human neuroblastoma SH-SY5Y cells. Mol. Cancer Ther. 6, 1425-1432 (2007).

109. Muhlethaler-Mottet, A., Meier, R., Flahaut, M., Bourloud, K. B., Nardou, K. \& Joseph, J. M. et al. Complex molecular mechanisms cooperate to mediate histone deacetylase inhibitors anti-tumour activity in neuroblastoma cells. Mol. Cancer 7, 55 (2008).

110. Condorelli, F., Gnemmi, I., Vallario, A., Genazzani, A. A. \& Canonico, P. L. Inhibitors of histone deacetylase (HDAC) restore the p53 pathway in neuroblastoma cells. Br. J. Pharmacol. 153, 657-668 (2008).

111. de Ruijter, A. J., Kemp, S., Kramer, G., Meinsma, R. J., Kaufmann, J. O. \& Caron, H. N. et al. The novel histone deacetylase inhibitor BL1521 inhibits proliferation and induces apoptosis in neuroblastoma cells. Biochem. Pharmacol. 68, 1279-1288 (2004).

112. Ouwehand, K., de Ruijter, A. J., van Bree, C., Caron, H. N. \& van Kuilenburg, A. B. Histone deacetylase inhibitor BL1521 induces a G1-phase arrest in neuroblastoma cells through altered expression of cell cycle proteins. FEBS Lett. 579, 1523-1528 (2005)

113. de Ruijter, A. J., Leen, R., Hoebink, J., Caron, H. N. \& van Kuilenburg, A. B. Antagonistic effects of sequential administration of BL1521, a histone deacetylase inhibitor, and gemcitabine to neuroblastoma cells. Cancer Lett. 233, 240-246 (2006).

114. Wang, Z., Hu, J., Zhou, D., Xu, Z., Panasci, L. C. \& Chen, Z. Trichostatin A inhibits proliferation and induces expression of p21WAF and p27 in human brain tumor cell lines. Ai Zheng 21, 1100-1105 (2002).

115. Hřebačková, J., Poljaková, J., Eckschlager, T., Hraběta, J., Procházka, P. \& Smutný, S. et al. Histone deacetylase inhibitors valproate and trichostatin A 
are toxic to neuroblastoma cells and modulate cytochrome P450 1A1, 1B1 and 3A4 expression in these cells. Interdiscip. Toxicol. 2, 205-210 (2009).

116. Carén, H., Fransson, S., Ejeskär, K., Kogner, P. \& Martinsson, T. Genetic and epigenetic changes in the common 1p36 deletion in neuroblastoma tumours. Br. J. Cancer 97, 1416-1424 (2007).

117. Politis, P. K., Akrivou, S., Hurel, C., Papadodima, O. \& Matsas, R. BM88/Cend1 is involved in histone deacetylase inhibition-mediated growth arrest and differentiation of neuroblastoma cells. FEBS Lett. 582, 741-748 (2008).

118. Hamner, J. B., Sims, T. L., Cutshaw, A., Dickson, P. V., Rosati, S. \& McGee, M. et al. The efficacy of combination therapy using adeno-associated virus-interferon beta and trichostatin A in vitro and in a murine model of neuroblastoma. J. Pediatr. Surg. 43, 177-183 (2008).

119. Kuljaca, S., Liu, T., Tee, A. E., Haber, M., Norris, M. D. \& Dwarte, T. et al. Enhancing the anti-angiogenic action of histone deacetylase inhibitors. Mol. Cancer 6, 68 (2007)

120. Poljakova, J., Hrebackova, J., Dvorakova, M., Moserova, M., Eckschlager, T. \& Hrabeta, J. et al. Anticancer agent ellipticine combined with histone deacetylase inhibitors, valproic acid and trichostatin $\mathrm{A}$, is an effective DNA damage strategy in human neuroblastoma. Neuro Endocrinol. Lett. 32, 101-116 (2011).

121. Wegener, D., Deubzer, H. E., Oehme, I., Milde, T., Hildmann, C. \& Schwienhorst, A. et al. HKI 46F08, a novel potent histone deacetylase inhibitor, exhibits antitumoral activity against embryonic childhood cancer cells. Anticancer Drugs 19, 849-857 (2008).

122. Deubzer, H. E., Ehemann, V., Kulozik, A. E., Westermann, F., Savelyeva, L. \& Kopp-Schneider, A. et al. Anti-neuroblastoma activity of Helminthosporium carbonum (HC)-toxin is superior to that of other differentiating compounds in vitro. Cancer Lett. 264, 21-28 (2008).

123. Panicker, J., Li, Z., McMahon, C., Sizer, C., Steadman, K. \& Piekarz, R. et al. Romidepsin (FK228/depsipeptide) controls growth and induces apoptosis in neuroblastoma tumor cells. Cell Cycle 9, 1830-1838 (2010).

124. Suzuki, T., Ota, Y., Ri, M., Bando, M., Gotoh, A. \& Itoh, Y. et al. Rapid discovery of highly potent and selective inhibitors of histone deacetylase 8 using click chemistry to generate candidate libraries. J. Med. Chem. 55, 9562-9575 (2012).

125. Wang, G., Edwards, H., Caldwell, J. T., Buck, S. A., Qing, W. Y. \& Taub, J. W. et al. Panobinostat synergistically enhances the cytotoxic effects of cisplatin, doxorubicin or etoposide on high-risk neuroblastoma cells. PLoS One $\mathbf{8}$, e76662 (2013).

126. Waldeck, K., Cullinane, C., Ardley, K., Shortt, J., Martin, B. \& Tothill, R. W. et al. Long term, continuous exposure to panobinostat induces terminal differentiation and long term survival in the TH-MYCN neuroblastoma mouse model. Int J. Cancer 139, 194-204 (2016).

127. Zhan, Q., Tsai, S., Lu, Y., Wang, C., Kwan, Y. \& Ngai, S. RuvBL2 is involved in histone deacetylase inhibitor PCl-24781-induced cell death in SK-N-DZ neuroblastoma cells. PLoS One 8, e71663 (2013).

128. Sholler, G. S., Currier, E. A., Dutta, A., Slavik, M. A., Illenye, S. A. \& Mendonca, M. C. F. et al. PCl-24781 (abexinostat), a novel histone deacetylase inhibitor, induces reactive oxygen species-dependent apoptosis and is synergistic with bortezomib in neuroblastoma. J. Cancer Ther. Res 2, 21 (2013).

129. Frumm, S. M., Fan, Z. P., Ross, K. N., Duvall, J. R., Gupta, S. \& VerPlank, L. et al. Selective HDAC1/HDAC2 inhibitors induce neuroblastoma differentiation. Chem. Biol. 20, 713-725 (2013).

130. Liu, P. Y., Xu, N., Malyukova, A., Scarlett, C. J., Sun, Y. T. \& Zhang, X. D. et al. The histone deacetylase SIRT2 stabilizes Myc oncoproteins. Cell Death Differ. 20 503-514 (2013)

131. Oehme, I., Deubzer, H. E., Wegener, D., Pickert, D., Linke, J. P. \& Hero, B. et al. Histone deacetylase 8 in neuroblastoma tumorigenesis. Clin. Cancer Res 15 , 91-99 (2009).

132. Subramanian, C., Jarzembowski, J. A., Opipari, A. W., Castle, V. P. \& Kwok, R. P. HDAC6 deacetylates Ku70 and regulates Ku70-Bax binding in neuroblastoma. Neoplasia 13, 726-734 (2011).

133. Keshelava, N., Davicioni, E., Wan, Z., Ji, L., Sposto, R. \& Triche, T. J. et al. Histone deacetylase 1 gene expression and sensitization of multidrug-resistant neuroblastoma cell lines to cytotoxic agents by depsipeptide. J. Nat/ Cancer Inst. 99, 1107-1119 (2007).

134. Berdasco, M., Ropero, S., Setien, F., Fraga, M. F., Lapunzina, P. \& Losson, R. et al. Epigenetic inactivation of the Sotos overgrowth syndrome gene histone methyltransferase NSD1 in human neuroblastoma and glioma. Proc. Natl Acad. Sci. USA 106, 21830-21835 (2009).

135. Hudlebusch, H. R., Skotte, J., Santoni-Rugiu, E., Zimling, Z. G., Lees, M. J. \& Simon, R. et al. MMSET is highly expressed and associated with aggressiveness in neuroblastoma. Cancer Res. 71, 4226-4235 (2011)

136. Wang, C., Liu, Z., Woo, C.-W., Li, Z., Wang, L. \& Wei, J. S. et al. EZH2 mediates epigenetic silencing of neuroblastoma suppressor genes CASZ1, CLU, RUNX3, and NGFR. Cancer Res. 72, 315-324 (2012).

137. Park, J. H., Szemes, M., Vieira, G. C., Melegh, Z., Malik, S. \& Heesom, K. J. et al. Protein arginine methyltransferase 5 is a key regulator of the MYCN oncoprotein in neuroblastoma cells. Mol. Oncol. 9, 617-627 (2015).

138. Tee, A. E., Ling, D., Nelson, C., Atmadibrata, B., Dinger, M. E. \& Xu, N. et al. The histone demethylase JMJD1A induces cell migration and invasion by upregulating the expression of the long noncoding RNA MALAT1. Oncotarget 5, 1793-1804 (2014).

139. Kuo, Y. T., Liu, Y. L., Adebayo, B. O., Shih, P. H., Lee, W. H. \& Wang, L. S. et al. JARID1B expression plays a critical role in chemoresistance and stem cell-like phenotype of neuroblastoma cells. PLoS One 10, 1-14 (2015).

140. Shahbazi, J., Scarlett, C. J., Norris, M. D., Liu, B., Haber, M. \& Tee, A. E. et al. Histone Deacetylase 2 and N-Myc reduce p53 protein phosphorylation at serine 46 by repressing gene transcription of tumor protein 53-induced nuclear protein 1. Oncotarget 5, 4257-4268 (2014).

141. Sun, Y., Liu, P. Y., Scarlett, C. J., Malyukova, A., Liu, B. \& Marshall, G. M. et al. Histone deacetylase 5 blocks neuroblastoma cell differentiation by interacting with N-Myc. Oncogene 33, 2987-2994 (2014).

142. Subramanian, C., Jarzembowski, J. A., Halsey, S. M., Kuick, R., Opipari, A. W. \& Castle, V. P. et al. CLU blocks HDACl-mediated killing of neuroblastoma. Tumor Biol. 32, 285-294 (2011).

143. Thole, T. M., Lodrini, M., Fabian, J., Wuenschel, J., Pfeil, S. \& Hielscher, T. et al. Neuroblastoma cells depend on HDAC11 for mitotic cell cycle progression and survival. Cell Death Dis. 8, e2635 (2017).

144. Glick, R. D., Swendeman, S. L., Coffey, D. C., Rifkind, R. A., Marks, P. A. \& Richon, V. M. et al. Hybrid polar histone deacetylase inhibitor induces apoptosis and CD95/CD95 ligand expression in human neuroblastoma. Cancer Res. 59, 4392-4399 (1999).

145. Coffey, D. C., Kutko, M. C., Glick, R. D., Swendeman, S. L., Butler, L. \& Rifkind, R. et al. Histone deacetylase inhibitors and retinoic acids inhibit growth of human neuroblastoma in vitro. Med. Pediatr. Oncol. 35, 577-581 (2000).

146. Coffey, D. C., Kutko, M. C., Glick, R. D., Acid, A. R., Butler, L. M. \& Heller, G. et al. The histone deacetylase inhibitor, $\mathrm{CHA}$, inhibits growth of human neuroblastoma xenografts in vivo, alone and synergistically with all-trans retinoic acid. Cancer Res. 61, 3591-3594 (2001).

147. Butler, L. M., Webb, Y., Agus, D. B., Higgins, B., Tolentino, T. R. \& Kutko, M. C. et al. Inhibition of transformed cell growth and induction of cellular differentiation by pyroxamide, an inhibitor of histone deacetylase. Clin. Cancer Res. 7, 962-970 (2001).

148. Jaboin, J., Wild, J., Hamidi, H., Khanna, C., Kim, C. J. \& Robey, R. et al. MS-27-275, an inhibitor of histone deacetylase, has marked in vitro and in vivo antitumor activity against pediatric solid tumors. Cancer Res. 62, 6108-6115 (2002).

149. Furchert, S. E., Lanvers-Kaminsky, C., Jürgens, H., Jung, M., Loidl, A. \& Frühwald, M. C. Inhibitors of histone deacetylases as potential therapeutic tools for high-risk embryonal tumors of the nervous system of childhood. Int. J. Cancer 120, 1787-1794 (2007).

150. Bayat Mokhtari, R., Baluch, N., Ka Hon Tsui, M., Kumar, S., S Homayouni, T. \& Aitken, $\mathrm{K}$. et al. Acetazolamide potentiates the anti-tumor potential of HDACi, MS-275, in neuroblastoma. BMC Cancer 17, 156 (2017).

151. Rozental, R., Faharani, R., Yu, Y., Johnson, J. M., Chan, S. O. \& Chiu, F. C. Sodium butyrate induces apoptosis in MSN neuroblastoma cells in a calcium independent pathway. Neurochem. Res. 29, 2125-2134 (2004). 